\title{
Evaluation of antihypertensive polyphenols Check for updates of barley (Hordeum vulgare L.) seedlings via their effects on angiotensin-converting enzyme (ACE) inhibition
}

\author{
Ji-Eun Ra ${ }^{1}$, So-Yeun Woo ${ }^{2}$, Hui Jin³ ${ }^{3}$ Mi Ja Lee ${ }^{2}$, Hyun Young Kim² ${ }^{2}$ Hyeonmi Ham², III-Min Chung ${ }^{1}$ \\ and Woo Duck Seo ${ }^{2^{*}}$ (I)
}

\begin{abstract}
Angiotensin-converting enzyme (ACE) is an important therapeutic target in the regulation of high blood pressure. This study was conducted to investigate the alterations in blood pressure associated with ACE inhibition activity of the polyphenols (1-10), including 3-O-feruloylquinic acid (1), lutonarin (2), saponarin (3), isoorientin (4), orientin (5), isovitexin (6), isoorientin-7-O-[6-sinapoyl]-glucoside (7), isoorientin-7-O-[6-feruloyl]-glucoside (8), isovitexin-7-0[6-sinapoyl]-glucoside (9), and isovitexin-7-O-[6-feruloyl]-glucoside (10), isolated from barley seedlings (BS). All the isolated polyphenols exhibited comparable $I_{50}$ values of ACE inhibition activity $(7.3-43.8 \mu \mathrm{M})$ with quercetin $(25.2 \pm 0.2 \mu \mathrm{M})$ as a positive control, and their inhibition kinetic models were identified as noncompetitive inhibition. Especially, compound 4 was revealed to be an outstanding ACE inhibitor $\left(I C_{50}=7.3 \pm 0.1 \mu \mathrm{M}, \mathrm{K}_{\mathrm{i}}=6.6 \pm 0.1 \mu \mathrm{M}\right)$. Based on the compound structure-activity relationships, the free hydroxyl groups of flavone-moieties and glucose connections at the A ring of the flavone moieties were important factors for inhibition of ACE. The alcohol extract of BS also demonstrated potent ACE inhibition activity $\left(66.5 \% \pm 2.2 \%\right.$ at $\left.5000 \mu \mathrm{g} \mathrm{mL}^{-1}\right)$. The polyphenols from BS had strong inhibitory activity on ACE and this study results suggest that BS can be used as an effective blood pressure regulator through ACE inhibition
\end{abstract}

Keywords: Angiotensin-converting enzyme, Barley seedlings, Enzyme kinetic, Flavone-glucosides, Hypertension, Hordeum vulgare L.

\section{Introduction}

Hypertension is a severe health problem, and its prevalence is increasing across many countries. The angiotensin I-converting enzyme (ACE) (EC 3.4.15.1) is the primary component of the renin-angiotensin-aldosterone system whose primary known functions are to convert precursor angiotensin I (Ang I) into angiotensin II

\footnotetext{
*Correspondence: swd2002@korea.kr

${ }^{2}$ Laboratory of Crop Resource Development, Crop Foundation Research Division, National Institute of Crop Science (NICS), Rural Development Administration (RDA), Wanju-gun 55365, Republic of Korea

Full list of author information is available at the end of the article
}

(Ang II) [1]. Ang II stimulates the synthesis and release of aldosterone from the adrenal cortex, which increases blood pressure [2]. Therefore, the inhibition of ACE has been considered as one of the effective remedies for the treatment of cardiovascular diseases. Consequently, ACE inhibitors, which can regulate and improve high blood pressure, are widely used for treating cardiovascular diseases.

Several studies have demonstrated that polyphenols have various biological and medicinal properties for the control of diseases in humans, such as antioxidant, antiatherosclerotic, antihypertensive, and anti-inflammatory activities [3-6]. However, the biological activities are 
dependent on their structural aspects such as the number or position of the free-OH substituents and the process of glycosylation [7-9]. Thus, each of the compound showed different biological activities and the activities should investigate with each of the target disease model. Barley seedlings (BS, young leaves of Hordeum vulgare L.) contain various polyphenols such as saponarin and lutonarin that promote health beneficial properties, including antioxidant, hypolipidemic [10], antiproliferative, and proapoptotic effects [11]. Although polyphenols are known to exert potent blood pressure regulation effects, the polyphenols isolated from BS have not been clearly investigated for their biological activity. In these reasons, this study was conducted to investigate the blood pressure regulation effect of BS extract and the isolated polyphenols through ACE inhibition.

\section{Materials and methods Plant material}

Barley (H. vulgare L.) seeds used in this study was cultivated in 2014 at the experimental field of the National Institute of Crop Science, Rural Development Administration, Miryang, Korea. BS were prepared as described previously [12]. In briefly, $200 \mathrm{~g}$ of barley seeds were imbibed in water for 1 day and germinated for 2 days in the dark. Germinated seeds were spread on commercial soil bed, and put in a growth chamber (DS-GC 768, Dongseo Science, Republic of Korea) at $22-23{ }^{\circ} \mathrm{C}$ and $60 \%$ humidity. Barley seedlings were collected 15 days later. The collected leaves were freeze-dried immediately after sampling. Prior to extraction, the leaves were pulverized in a 100 mesh. All sample masses were calculated on the basis of dry weight.

\section{Instruments and reagents}

For measuring antihypertensive activity, 4-[3-(4-iodophenyl)-2-(4-nitrophenyl)-2H-5-tetrazolio]1,3-benzene disulfonate sodium salt (water-soluble tetrazolium salt, WST-1) was obtained from Dojindo Laboratories (Kumamoto, Japan). ACE from rabbit lung and aminoacylase (EC 3.5.1.14) were obtained from Sigma-Aldrich (MO, USA). Fluorescence spectrophotometer were used SpectraMax M5 (Molecular Devices, CA, USA).

\section{Preparation of ACE inhibitors}

One gram of dried leaves powder $(1 \mathrm{~g})$ was extracted with $20 \mathrm{~mL}$ of solvent at $37{ }^{\circ} \mathrm{C}$ for $24 \mathrm{~h}$. Three different solvent extraction systems were used (water, methanol, and hexane), and then the extract was filtered. The filtered crude extract was concentrated using an evaporator under reduced pressure condition at $50{ }^{\circ} \mathrm{C}$. In the previous study [13], the isolated polyphenolic compounds were identified using spectroscopic data including 2D-NMR and by comparison with previously published data.

\section{ACE inhibition assay procedure}

The ACE inhibition assay was performed according to a procedure previously described in the literature with some modifications $[14,15]$. The synthesized substrate 3-hydroxybutyrylglycyl-glycyl-glycine (3HB-GGG) was applied in the assay of ACE inhibition activities. 3HB-GGG was synthesized according to a previously described procedure [14]. The sample solutions, which included the extracts and the compounds isolated from BS, were dissolved in $200 \mathrm{mM}$ sodium borate buffer with $\mathrm{pH}$ 8.3. Then, $20 \mu \mathrm{L}$ of the sample solution was premixed with $20 \mu \mathrm{L}$ of $1.2 \mathrm{mM}$ 3HB-GGG, which was earlier dissolved in $50 \mathrm{mM}$ sodium borate buffer (including $300 \mathrm{mM} \mathrm{NaCl}, \mathrm{pH}$ 8.3). Then, $20 \mu \mathrm{L}$ of an enzyme working solution, which was dissolved in aminoacylase $(86 \mathrm{kU}$ $\mathrm{mL}^{-1}$ ) with $50 \mathrm{mM}$ sodium borate buffer ( $\left.\mathrm{pH} 8.3\right)$, and ACE $\left(0.1 \mathrm{U} \mathrm{mL}^{-1}\right)$ were added and mixed well to start the reaction at $37^{\circ} \mathrm{C}$. The reaction resulted in the production of $3 \mathrm{HB}$, which is a 3-hydroxybutyrate derived from 3HBGGG. The 3HB levels were determined using $200 \mu \mathrm{L}$ of an indicator working solution. This indicator working solution was composed of $0.333 \mathrm{mM} \mathrm{NAD}{ }^{+}, 0.333 \mathrm{mM}$ WST-1, $0.1 \mathrm{mM}$ EDTA, diaphorase $\left(0.633 \mathrm{U} \mathrm{mL}^{-1}\right)$, and 3-hydroxybutyrate dehydrogenase $\left(0.700 \mathrm{U} \mathrm{mL}^{-1}\right)$. WST-1 formazan was measured at $490 \mathrm{~nm}$ for $60 \mathrm{~min}$ by spectrophotometer. The ACE inhibition rate (\%) was calculated according to the following Eq. (a) $[16,17]$ :

$$
\text { Inhibition rate }(\%)=100\left[1 /\left(1+\left([\mathrm{I}] / \mathrm{IC}_{50}\right)\right]\right.
$$

where [I]: inhibitor concentration and $\mathrm{IC}_{50}$ : concentration of an inhibitor that resulted in 50\% inhibition of an enzyme.

The dose-dependent enzyme inhibition activity was determined using four concentrations of each compound. The $\mathrm{IC}_{50}$ value was calculated using a linear regression analysis plot of ACE inhibition \% vs. concentration of each compound. The inhibition constant $\left(\mathrm{K}_{\mathrm{i}}\right)$ values were calculated using Eq. (b) $[16,17]$ :

$$
\mathrm{K}_{\mathrm{i}}=\mathrm{IC}_{50} /\left[1+\left([\mathrm{S}] / \mathrm{K}_{\mathrm{m}}\right)\right]
$$

where [S]: substrate concentration, $\mathrm{K}_{\mathrm{m}}$ : Michaelis constant, the substrate concentration that provides a reaction velocity that is half of the maximal velocity obtained under saturating substrate conditions. The natural product quercetin was used as a positive control. 


\section{Enzyme kinetic analysis}

The inhibition kinetics of the enzyme by the isolated compounds was determined according to the Michaelis-Menten kinetic model, $\mathrm{V}=\mathrm{V}_{\max }[\mathrm{S}] /\left(\mathrm{K}_{\mathrm{m}}+[\mathrm{S}]\right)$. Lineweaver-Burk plots (1/V vs. 1/[S]) and Dixon plots $\left(\mathrm{V}_{\max }\right.$ vs. [I] with varying concentrations of substrate), which were derived using the saturation curves, were used to determine the inhibitor type according to the following Eq. (c) [16, 17]:

$$
1 / \mathrm{V}=\left(\mathrm{K}_{\mathrm{m}} / \mathrm{V}_{\max }\right)[\mathrm{S}]+1 / \mathrm{V}_{\max }
$$

where V: reaction rate, $\mathrm{K}_{\mathrm{m}}$ : Michaelis constant, [S]: substrate concentration, $\mathrm{V}_{\max }$ : maximum reaction rate.

Kinetic parameters such as $\mathrm{K}_{\mathrm{m}}, \mathrm{V}_{\max }$, and $\mathrm{K}_{\mathrm{i}}$ were calculated using the Sigma Plot (SPSS Inc., Chicago, IL, USA) software.

\section{Statistical analysis}

All measurements were made in triplicate. The results were subjected to analysis of variance using the sigma plot to analyze the differences. Differences were considered to be significant at $p<0.05$. Multiple comparisons were analyzed using one-way analysis of variance, followed by Dunnett's post hoc test, and the results are expressed as mean values with their respective standard deviations.

\section{Results and discussion}

\section{Quantitative isolation and structure identification}

In the present study conducted to determine a natural therapeutic approach for the treatment of high blood pressure through the inhibition of ACE, three different BS extracts were prepared using water, methanol, and hexane and their ACE inhibition activities were compared (Additional file 1: Table S1). The methanol extract of BS showed the dominant ACE inhibition activity of $66.5 \% \pm 2.2 \%$ than the water extract with the ACE inhibition activity of $56.1 \% \pm 0.8 \%$, whereas the lowest activity of $32.1 \% \pm 1.1 \%$ was obtained with the hexane extract at $500 \mu \mathrm{g} / \mathrm{mL}$. In the previous study [13], 10 polyphenolic compounds (1-10) were isolated and confirmed as major polyphenolics in barley seedlings. Therefore, we isolated 10 polyphenolic compounds from $150 \mathrm{~g}$ of BS extract as described preciously and identified by spectroscopic data (NMR spectrum are available as Additional file 1: Figs. S1-60). These 10 polyphenolic compounds (1-10) were 3-O-feruloylquinic acid (1), lutonarin (2), saponarin (3), isoorientin (4), orientin (5), isovitexin (6), isoorientin-7-O-[6-sinapoyl]glucoside (7), isoorientin-7-O-[6-feruloyl]-glucoside (8), isovitexin-7-O-[6-sinapoyl]-glucoside (9), and
isovitexin-7-O-[6-feruloyl]-glucoside (10) (Fig. 1). The weight contribution of the total isolated polyphenols and each isolated compound 1-10 were $1.3 \%, 16.7 \%$, $71.4 \%, 1.5 \%, 1.5 \%, 1.1 \%, 1.4 \%, 1.8 \%, 1.2 \%$, and $2.1 \%$, respectively (LC chromatogram of the BS extract and the content of the isolated polyphenols are available as Additional file 1: Fig. S61 and Table S2, respectively).

\section{ACE inhibition activity}

The inhibitory activities of the compounds 1-10 on ACE were investigated using a fluorometric method [14, 15]. The reaction kinetic parameters of the ACE inhibition effect for the hydrolysis of 3HB-GGG were obtained using the substrate concentration $(200-800 \mu \mathrm{M})$ versus the enzyme concentration of ACE $(0.5-0.8 \mathrm{U} / \mathrm{mL})$ with aminoacylase $(86 \mathrm{kU} / \mathrm{mL})$. And the formation of $3 \mathrm{HB}$ was compared with quercetin as a positive control which is a well-known potent inhibitor of ACE among polyphenols [18-20]. Compounds 1-10 exhibited significant dose-dependent inhibition of ACE (Fig. 2a); the inhibition concentration $\left(\mathrm{IC}_{50}\right)$ values $(\mu \mathrm{M})$ of compounds 1-10 are presented in Table 1. All compounds exhibited excellent ACE inhibition activities, with the $\mathrm{IC}_{50}$ values ranging between 7.3 and $43.8 \mu \mathrm{M}$ (Table 1), compared with quercetin $\left(\mathrm{IC}_{50}=25.2 \mu \mathrm{M}, \mathrm{K}_{\mathrm{i}}=24.9 \mu \mathrm{M}\right)$. As shown in Fig. 2b, as the concentration of compound 4 was increased, the enzyme activity was rapidly diminished and resulted in lowering of the slope of the line. Furthermore, the generation of $3 \mathrm{HB}$ by the action of $\mathrm{ACE}$ increased with the increase in ACE concentration. Therefore, the inhibition of compound $\mathbf{4}$ was reversible against ACE $[16,17,21]$.

The most potential inhibitor to ACE was compound 4 whose $\mathrm{IC}_{50}$ value was $7.3 \mu \mathrm{M}\left(\mathrm{K}_{\mathrm{i}}=6.6 \mu \mathrm{M}\right)$, whereas compound 1 that does not have the flavone moiety exhibited the least activity with an $\mathrm{IC}_{50}$ value of $43.8 \mu \mathrm{M}\left(\mathrm{K}_{\mathrm{i}}=41.4 \mu \mathrm{M}\right)$. The number of hydroxyl groups in the B-ring had a positive effect on the inhibitory activity (compound 4: $\mathrm{IC}_{50}=7.3 \mu \mathrm{M}$ vs. compound 6: $\mathrm{IC}_{50}=26.1 \mu \mathrm{M}$, and compound $2: \mathrm{IC}_{50}=15.9 \mu \mathrm{M}$ vs. compound $3: \mathrm{IC}_{50}=24.4 \mu \mathrm{M}$ ). This result suggested that the free hydroxyl groups of flavone moieties in polyphenols formed chelates with zinc ions, which are a part of the ACE active site [22]. As a consequence of these reactions, the activity of ACE was interfered. A previous study also reported similar results wherein the number of hydroxyl groups in hydroxybenzoic acid plays a role as the key factor on the activity of ACE [23]. The glucose connections at the A-ring of the flavone moieties were important factors that also had an influence on the inhibition potential. For example, the flavone 6-C-glucose moiety at the A-ring of flavones-glucosides $4\left(\mathrm{~K}_{\mathrm{i}}=6.6 \mu \mathrm{M}\right)$ was more effective than 8-glucosylated-flavone $5\left(K_{\mathrm{i}}=26.8 \mu \mathrm{M}\right)$. 


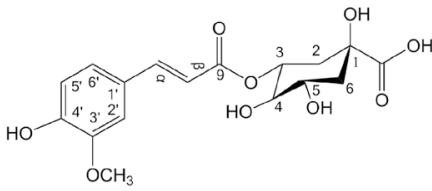

3-O-feruloylquinic acid (1)

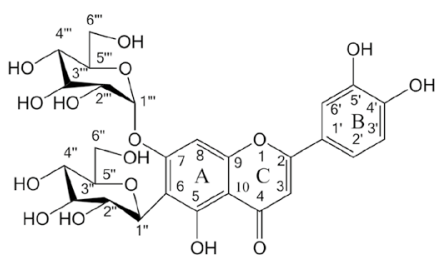

Lutonarin (2)

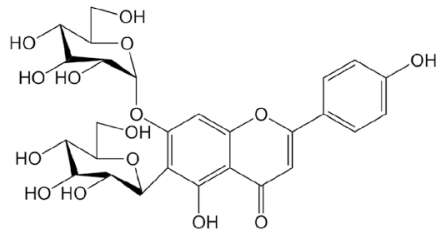

Saponarin (3)<smiles></smiles>

Isoorientin $(4)$<smiles>O=c1cc(-c2ccc(O)c(O)c2)oc2c(C(O)CO)c(O)cc(O)c12</smiles>

Orientin (5)<smiles></smiles>

Isovitexin (6)

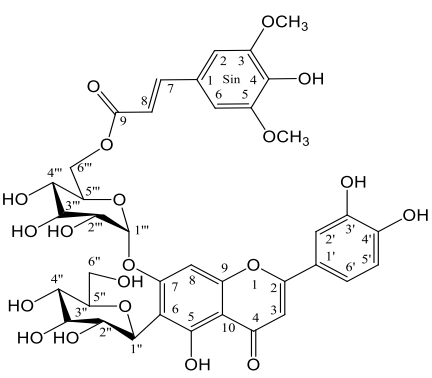

Isoorientin-7-O-[6-sinapoyl]-glucoside (7)

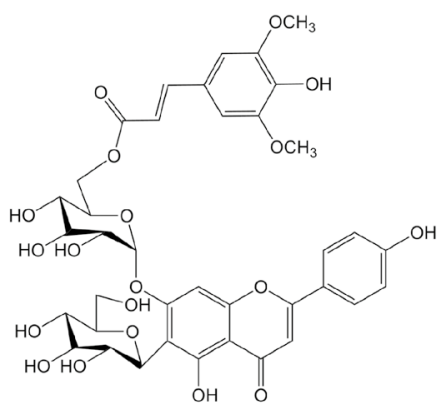

Isovitexin-7-O-[6-sinapoyl]-glucoside (9)

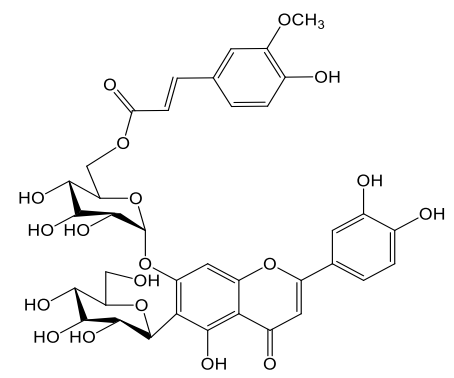

Isoorientin-7-O-[6-feruloyl]-glucoside (8)

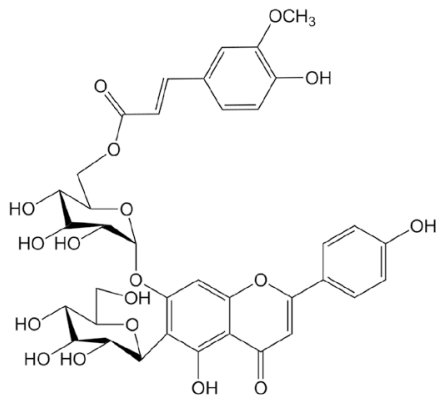

Isovitexin-7-O-[6-feruloyl]-glucoside (10)

Fig. 1 The structures of compounds 1-10 isolated from BS used in this study. The polyphenolic compounds 1-10 were 3-O-feruloylquinic acid 1, lutonarin (2), saponarin (3), isoorientin (4), orientin (5), isovitexin (6), isoorientin-7-O-[6-sinapoyl]-glucoside (7), isoorientin-7-O-[6-feruloyl]-glucos ide (8), isovitexin-7-O-[6-sinapoyl]-glucoside (9), and isovitexin-7-O-[6-feruloyl]-glucoside (10); these isolated compounds have been identified with spectroscopic data in a previous study [13] 

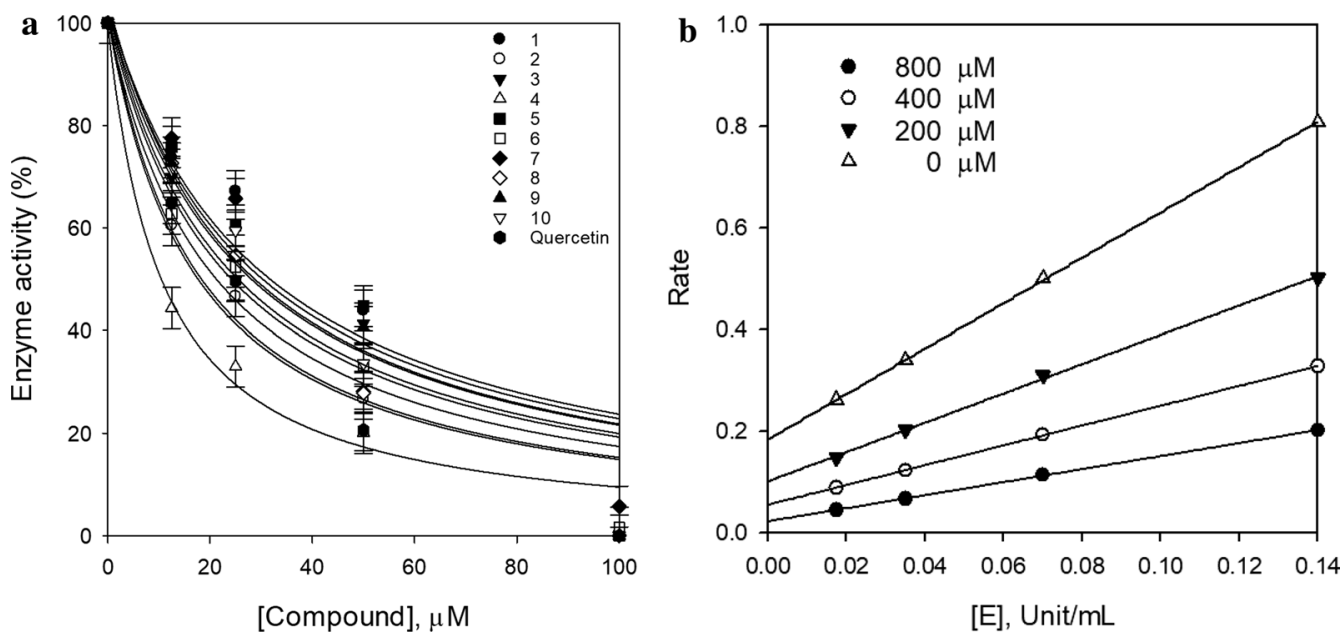

Fig. 2 Effect of compounds on the activity of ACE for the hydrolysis of 3HB-GGG. a Dose-dependent ACE inhibition activity of the compounds (1-10 and quercetin as positive control). b Relationship between the hydrolytic activity of ACE and the enzyme concentrations at different concentrations of compound $\mathbf{4}$. The concentrations of compound $\mathbf{4}$ for each curve were $\mathbf{0}, 200,400$, and $800 \mu \mathrm{M}$ from top to bottom, respectively. Values are expressed as mean \pm deviation $(n=3)$

Table 1 Comparisons of an angiotensin-converting enzyme (ACE) inhibition effects on the compounds (1-10) from barley seedlings (BS)

\begin{tabular}{lcc}
\hline Compound & ACE inhibition & \\
\cline { 2 - 3 } & $\mathbf{I C}_{\mathbf{5 0}}(\boldsymbol{\mu} \mathbf{M})^{\mathbf{a}}$ & Type of inhibition, $\boldsymbol{K}_{\boldsymbol{l}}(\boldsymbol{\mu} \mathbf{M})^{\mathbf{b}}$ \\
\hline 3-O-feruloylquinic acid (1) & $43.8 \pm 0.6$ & Noncompetitive, $41.4 \pm 1.2$ \\
Lutonarin (2) & $15.9 \pm 1.1$ & Noncompetitive, $15.9 \pm 0.3$ \\
Saponarin (3) & $24.4 \pm 1.2$ & Noncompetitive, $24.1 \pm 0.9$ \\
Isoorientin (4) & $7.3 \pm 0.1$ & Noncompetitive, $6.6 \pm 1.6$ \\
Orientin (5) & $24.4 \pm 1.6$ & Noncompetitive, $26.8 \pm 1.7$ \\
Isovitexin (6) & $26.1 \pm 0.5$ & Noncompetitive, $21.1 \pm 0.3$ \\
Isoorientin-7-O-[6-sinapoyl]-glucoside (7) & $36.2 \pm 0.8$ & Noncompetitive, $32.1 \pm 1.3$ \\
Isoorientin-7-O-[6-feruloyl]-glucoside (8) & $29.8 \pm 0.5$ & Noncompetitive, $28.4 \pm 0.9$ \\
Isovitexin-7-O-[6-sinapoyl]-glucoside (9) & $40.7 \pm 0.1$ & Noncompetitive, $37.2 \pm 1.1$ \\
Isovitexin-7-O-[6-feruloyl]-glucoside (10) & $35.4 \pm 0.1$ & Noncompetitive, $33.2 \pm 0.4$ \\
Quercetinc & $25.2 \pm 0.2$ & Noncompetitive, $24.9 \pm 1.7$ \\
\hline Al & &
\end{tabular}

All extracts were examined in a set of experiments repeated three times

a $\mathrm{IC}_{50}$ values of compounds represent the concentration that caused $50 \%$ enzyme activity loss

b Values of inhibition constant

c This compound was used as a positive control

And, the inhibition activity on ACE tended to decrease with the presence of sinapoyl-glucoside or feruloyl-glucoside at C-7 of the A-ring (compound 4: $\mathrm{IC}_{50}=7.3 \mu \mathrm{M}$ and compound 6: $\mathrm{IC}_{50}=26.1 \mu \mathrm{M}$ vs. compound 7: $\mathrm{IC}_{50}=36.2 \mu \mathrm{M}$, compound 8: $\mathrm{IC}_{50}=29.8 \mu \mathrm{M}$, compound 9: $\mathrm{IC}_{50}=40.7 \mu \mathrm{M}$, and compound 10: $\mathrm{IC}_{50}=35.4 \mu \mathrm{M}$ ). Also, compounds 2 and 3, major polyphenols in BS [24], exhibited the excellent ACE inhibition activities, with their $\mathrm{IC}_{50}$ values being 15.9 and $24.4 \mu \mathrm{M}$, respectively.
In plant flavonoids, a family of polyphenolic compounds, including anthocyanins (e.g., delphinidin-3-Osambubioside and cyanidin-3-O-sambubioside) [25], flavonols (e.g., quercetin glucuronide and quercetin-3$O$-(6"-galoyl)-galactoside) [26], and flavan-3-ols (e.g., epicatechin dimer, epicatechin tetramer, and epicatechin hexamer) $[27,28]$, have been investigated for their ACE inhibition effect. However, they exhibited less 

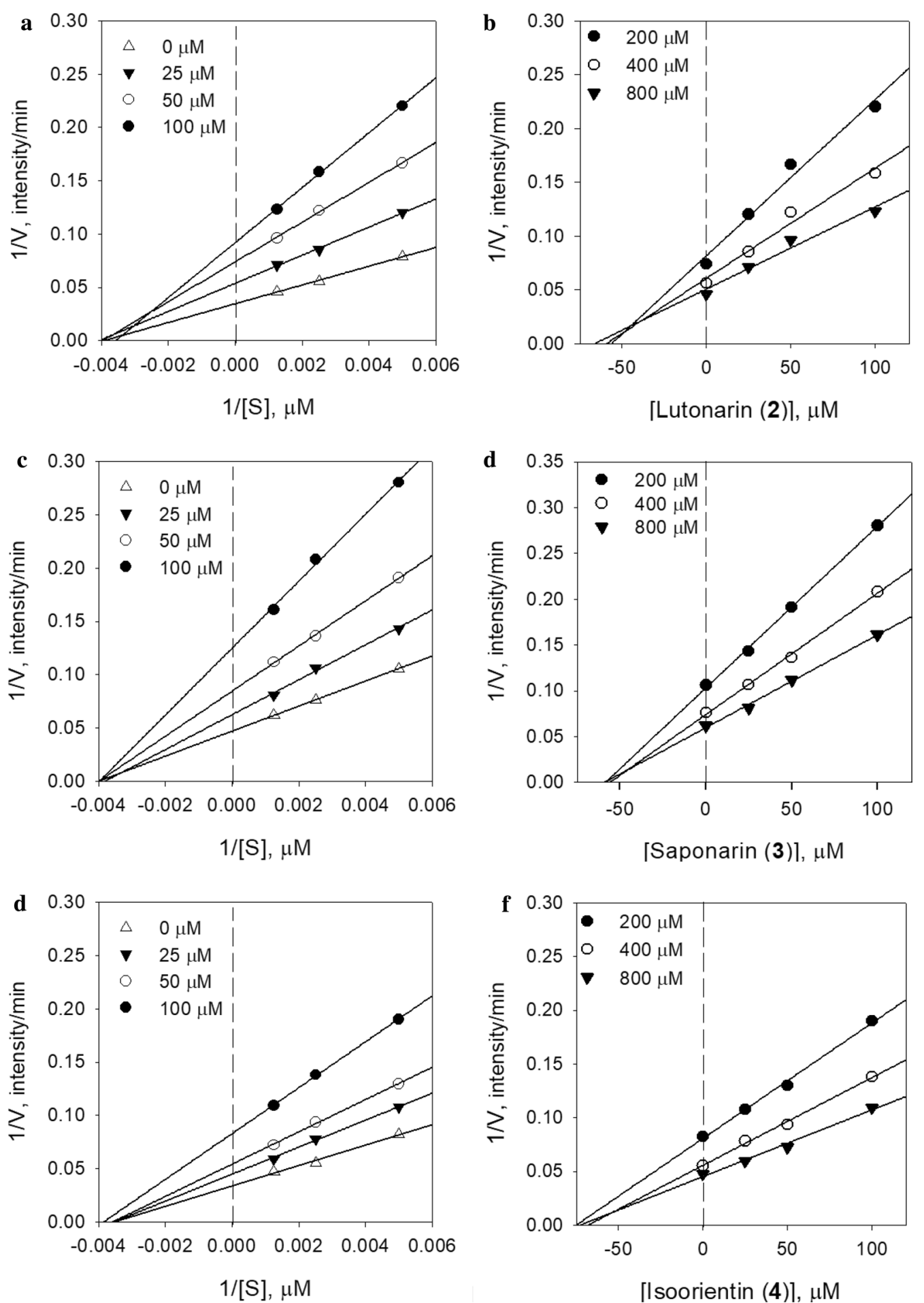

Fig. 3 Determination of the inhibition type for compound $\mathbf{2}-\mathbf{6}$, which showed the predominant ACE inhibition activity, and quercetin as a positive control. a, $\mathbf{c}, \mathbf{e}, \mathbf{g}, \mathbf{i}$, and $\mathbf{k}$ represent the Lineweaver-Burk plots for compounds $\mathbf{2}-\mathbf{6}$ and quercetin on the ACE inhibition activity for the hydrolysis of 3 HB-GGG in the presence of four different concentrations of compounds, $0,25,50$, and $100 \mu \mathrm{M}$, a for lutonarin (2), $\mathbf{c}$ for saponarin (3), e for isoorientin (4), $\mathbf{g}$ for orientin (5), i for isovitexin (6) and $\mathbf{k}$ for quercetin, respectively. $\mathbf{b}, \mathbf{d}, \mathbf{f}, \mathbf{h}, \mathbf{j}$, and $\mathbf{I}$ represent the Dixon plot for compound $\mathbf{2}-\mathbf{6}$ and quercetin on the ACE inhibition activity for the hydrolysis of 3HB-GGG in the presence of four different concentrations of compounds, $0,25,50$, and $100 \mu \mathrm{M}, \mathbf{b}$ for lutonarin (2), $\mathbf{d}$ for saponarin (3), $\mathbf{f}$ for isoorientin (4), $\mathbf{h}$ for orientin (5), $\mathbf{j}$ for isovitexin (6) and I for quercetin, respectively 

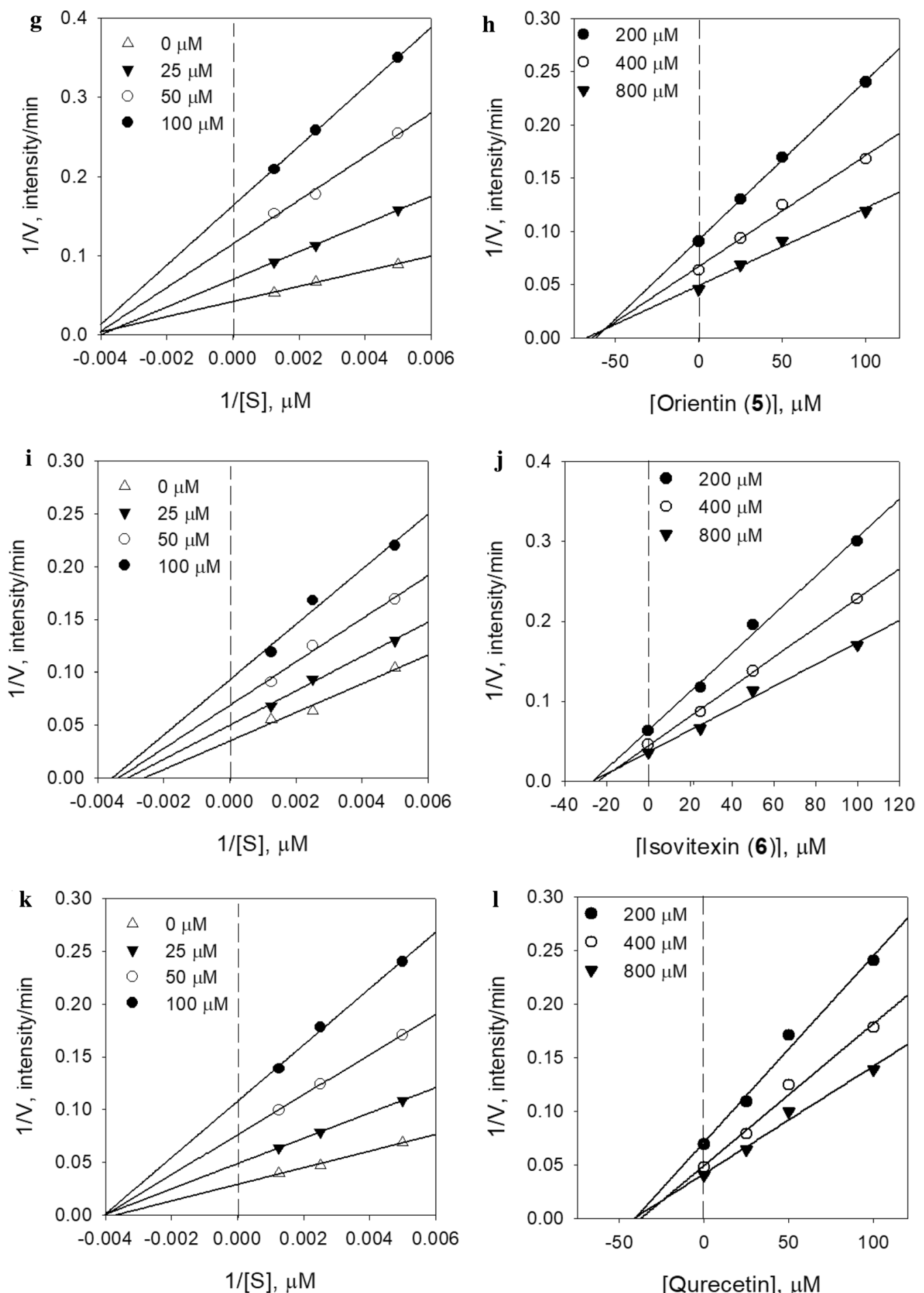

Fig. 3 continued

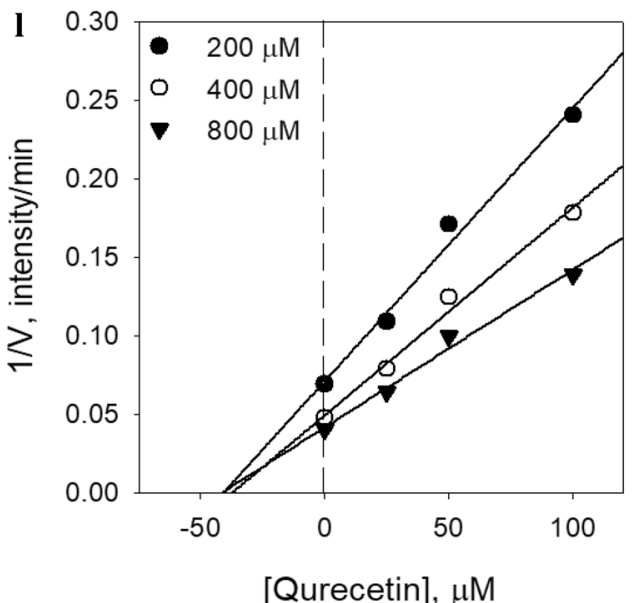

ACE inhibition activity compared to that of other isolated flavonoids investigated in the present study.

The Lineweaver-Burk plot is useful in diagnosing inhibitor modality as a means of estimating the kinetic parameters $\mathrm{K}_{\mathrm{m}}$ and $\mathrm{V}_{\max }$. The Dixon plot is also useful in determining the inhibitor $\mathrm{K}_{\mathrm{i}}$, which is the dissociation constant, when the inhibitor binds to the enzyme $[16,17]$. These two kinetic plots of compounds 2-6, 
including quercetin, which exhibited the predominant ACE inhibition activity, are depicted in Fig. 3. In the Dixon plot (Fig. 3b, d, f, h, j, and l), when the concentrations of compounds $\mathbf{2 - 5}$ and $\mathbf{6}$ were increased, the $\mathrm{V}_{\max }$ values were decreased without changing the $\mathrm{K}_{\mathrm{m}}$ value. In addition, as shown in Lineweaver-Burk plot (Fig. 3a, c, e, g, i, and k), three different concentrations of compounds 2-6 converged at one point on the negative $\mathrm{x}$-axis, respectively. These data indicated that compounds 2-6 were noncompetitive inhibitors of ACE and have affinity for both the free ACE and the ACEsubstrate complex. The inhibitor constant $K_{i}$ values, which represent the degree of binding of the inhibitor to the enzyme, were calculated using the Dixon plot. The $K_{\mathrm{i}}$ values for compounds $\mathbf{2 - 6}$ and quercetin were $15.9,24.1,6.6,26.8,21.1$, and $24.9 \mu \mathrm{M}$, respectively. Among these compounds, the affinity of compound 4 was the highest. The detailed information of other compounds has been described in Additional file 1: Fig. S62. Because of the structural nonsimilarity with the natural substrate of $\mathrm{ACE}$, this noncompetitive inhibition for ten compounds (1-10) was accepted in this experiment.

The ACE inhibitory activity was highest in methanol extract of barley seedlings, and isolated polyphenols from methanol extract were exhibited notable ACE inhibition activity. This result implied that the methanol extract contains high levels of ACE inhibitors. This was consistent with a previous investigation, wherein methanol was found to be an appropriate solvent for the maximum extraction of polyphenols from natural sources [29]. Therefore, the ACE inhibition activities of BS methanol extracts were derived from the polyphenolic compounds present in BS. In conclusion, the results of our study have highlighted the therapeutic potential of BS, which can be used as a healthy food and additive, for lowering blood pressure in humans.

\section{Supplementary information}

Supplementary information accompanies this paper at https://doi. org/10.1186/s13765-020-00519-9.

Additional file 1. NMR spectrum, LC chromatogram and content of the 10 isolated compounds, ACE inhibition activity of BS extracts, inhibition kinetic mode of compounds 1,7,8, 9, and 10 are available as supplementary materials.

\section{Acknowledgements}

This work was carried out with the support of the "Cooperative Research Program for Agriculture Science \& Technology Development (Project title: Identification and standardization of ameliorating effect on bioactive compounds for blood lipid levels from crop sprouts, Project No.: PJ01324902)", Rural Development Administration (RDA), Republic of Korea.
Authors' contributions

$J$-ER were contributors in writing the manuscript and performing major data analysis. S-YW was performing data analysis of enzyme assay. H-J, HYK and $\mathrm{HH}$ performed the minor experiments and prepared the raw materials. MJL and IMC data were contributed in discussion of experimental results, JHL was contributed in design a major experiment, WDS planned and led this research. All authors read and approved the final manuscript.

\section{Funding}

Funding received from Rural Development Administration.

\section{Availability of data and materials}

All data generated or analysed during this study are included in this published article and its additional files.

\section{Competing interests}

The authors declare that they have no competing interests.

\section{Author details}

${ }^{1}$ Department of Crop Science, College of Sanghuh Life Science, Konkuk University, Seoul 05029, Republic of Korea. ${ }^{2}$ Laboratory of Crop Resource Development, Crop Foundation Research Division, National Institute of Crop Science (NICS), Rural Development Administration (RDA), Wanju-gun 55365, Republic of Korea. ${ }^{3}$ Myongji University, 4 F SanHak Bldg, Yongin-si, Gyeonggi-do 17058, Republic of Korea.

Received: 17 April 2020 Accepted: 30 June 2020

Published online: 14 July 2020

\section{References}

1. Ondetti MA, Rubin B, Cushman DW (1977) Design of specific inhibitors of angiotensin-converting enzyme: new class of orally active antihypertensive agents. Science 196:441-444

2. Hammoud RA, Vaccari CS, Nagamia SH, Khan BV (2007) Regulation of the renin-angiotensin system in coronary atherosclerosis: a review of the literature. Vasc Health Risk Manag 3:937-945

3. Choi SH, Seo H-S, Lee KR, Lee SH, Lee JH (2018) Effect of cultivars and milling degrees on free and bound phenolic profiles and antioxidant activity of black rice. Appl Biol Chem 61:49-60

4. Gouedard C, Barouki R, Morel Y (2004) Dietary polyphenols increase paraoxonase 1 gene expression by an aryl hydrocarbon receptor-dependent mechanism. Mol Cell Biol 24:5209-5222

5. Actis-Goretta L, Ottaviani Jl, Keen CL, Fraga CG (2003) Inhibition of angiotensin converting enzyme (ACE) activity by flavan-3-ols and procyanidins. FEBS Lett 555:597-600

6. Kwon J-H, Oh H-J, Lee D-S, In S-J, Seo K-H, Jung J-W, Cha B-J, Lee DY, Baek $\mathrm{N}-\mathrm{I}$ (2019) Pharmacological activity and quantitative analysis of flavonoids isolated from the flowers of Begonia semperflorens Link et Otto. Appl Bio Chem 62:11

7. Farhoosh R, Johnny S, Asnaashari M, Molaahmadibahraseman N, Sharif A (2016) Structure-antioxidant activity relationships of o-hydroxyl, o-methoxy, and alkyl ester derivatives of p-hydroxybenzoic acid. Food Chem 194:128-134

8. Rice-Evans CA, Miller NJ, Bolwell PG, Bramley PM, Pridham JB (1995) The relative antioxidant activities of plant-derived polyphenolic flavonoids. Free Radic Res 22:375-383

9. Zhang K, Das NP (1994) Inhibitory effects of plant polyphenols on rat liver glutathione S-transferases. Biochem Pharmacol 47:2063-2068

10. Yu YM, Wu CH, Tseng YH, Tsai CE, Chang WC (2002) Antioxidative and hypolipidemic effects of barley leaf essence in a rabbit model of atherosclerosis. Jpn J Pharmacol 89:142-148

11. Robles-Escajeda E, Lerma D, Nyakeriga AM, Ross JA, Kirken RA, Aguilera RJ, Varela-Ramirez A (2013) Searching in mother nature for anti-cancer activity: anti-proliferative and pro-apoptotic effect elicited by green barley on leukemia/lymphoma cells. PLoS ONE 8:e73508

12. Seo WD, Yuk HJ, Curtis-Long MJ, Jang KC, Lee JH, Han SI, Kang HW, Nam MH, Lee S-J, Lee JH, Park KH (2013) Effect of the growth stage and cultivar on policosanol profiles of barley sprouts and their adenosine 
5'-monophosphate-activated protein kinase activation. J Agric Food Chem 61:1117-1123

13. Park MJ, Ra JE, Seo KH, Jang KC, Han SI, Lee JH, Kang Y-H, Nam MH, Seo WD (2014) dentification and evaluation of flavone-glucosides isolated from barley sprout and their inhibitory activity against bacterial neuraminidase. Nat Prod Commun 9:1469-1472

14. Lam LH, Shimamura T, Sakaguchi K, Noguchi K, Ishiyama M, Fujimura Y, Ukeda H (2007) Assay of angiotensin I-converting enzyme-inhibiting activity based on the detection of 3-hydroxybutyric acid. Anal Biochem 364:104-111

15. Lam LH, Shimamura T, Manabe S, Ishiyama M, Ukeda H (2008) Assay of angiotensin I-converting enzyme-inhibiting activity based on the detection of 3-hydroxybutyrate with water-soluble tetrazolium salt. Anal Sci 24:1057-1060

16. Copeland RA (2004) Enzymes: a practical introduction to structure, mechanism, and data analysis, 2nd edn. Wiley, New York

17. Teng $H$, Chen L, Fang T, Yuan B, Lin Q (2017) Rb2 inhibits a-glucosidase and regulates glucose metabolism by activating AMPK pathways in HepG2 cells. J Funct Foods 28:306-313

18. Balasuriya N, Rupasinghe HP (2012) Antihypertensive properties of flavonoid-rich apple peel extract. Food Chem 135:2320-2325

19. Häckl LPN, Cuttle G, Dovichi SS, Lima-Landman MT, Nicolau M (2002) Inhibition of angiotensin-converting enzyme by quercetin alters the vascular response to bradykinin and angiotensin I. Pharmacology 65:182-186

20. Larson AJ, Symons JD, Jalili T (2012) Therapeutic potential of quercetin to decrease blood pressure: review of efficacy and mechanisms. Adv Nutr 3:39-46

21. Ra J-E, Seo KH, Ko JY, Lee M-J, Kang HJ, Kim SL, Chung IM, Seo WD (2015) Antioxidative effect and neuraminidase inhibitory activity of polyphenols isolated from a new Korean red waxy sorghum (Sorghum bicolor L. CV. Hwanggeumchalsusu). J Life Sci 25:786-794
22. Chen CH, Lin JY (1992) Inhibition of Angiotensin-I-Converting Enzyme by Tetrahydroxyxanthones Isolated from Tripterospermum Lanceolatum. J Nat Prod 55:691-695

23. Al Shukor N, Van Camp J, Gonzales GB, Staljanssens D, Struijs K, Zotti MJ, Raes K, Smagghe G (2013) Angiotensin-converting enzyme inhibitory effects by plant phenolic compounds: a study of structure activity relationships. J Agric Food Chem 61:11832-11839

24. Kamiyama M, Shibamoto T (2012) Flavonoids with potent antioxidant activity found in young green barley leaves. J Agric Food Chem 60:6260-6267

25. Ojeda D, Jimenez-Ferrer E, Zamilpa A, Herrera-Arellano A, Tortoriello J, Alvarez L (2010) Inhibition of angiotensin convertin enzyme (ACE) activity by the anthocyanins delphinidin- and cyanidin-3-O-sambubiosides from Hibiscus sabdariffa. J Ethnopharmacol 127:7-10

26. Kiss A, Kowalski J, Melzig MF (2004) Compounds from Epilobium angustifolium inhibit the specific metallopeptidases ACE, NEP and APN. Planta Med 70:919-923

27. Ottaviani Jl, Actis-Goretta L, Villordo JJ, Fraga CG (2006) Procyanidin structure defines the extent and specificity of angiotensin I converting enzyme inhibition. Biochimie 88:359-365

28. Actis-Goretta L, Ottaviani JI, Fraga CG (2006) Inhibition of angiotensin converting enzyme activity by flavanol-rich foods. J Agric Food Chem $54: 229-234$

29. Kang NS, Lee JH (2011) Characterisation of phenolic phytochemicals and quality changes related to the harvest times from the leaves of Korean purple perilla (Perilla frutescens). Food Chem 124:556-562

\section{Publisher's Note}

Springer Nature remains neutral with regard to jurisdictional claims in published maps and institutional affiliations.

\section{Submit your manuscript to a SpringerOpen ${ }^{\circ}$ journal and benefit from:}

- Convenient online submission

- Rigorous peer review

- Open access: articles freely available online

- High visibility within the field

- Retaining the copyright to your article

Submit your next manuscript at springeropen.com 